\title{
巴丹吉林沙漠腹地降水事件后的沙山蒸发观测
}

\author{
马宁, 王乃昂”, 赵力强, 张振瑜, 董春雨, 沈士平 \\ 兰州大学资源环境学院, 兰州大学干旱区气候变化与水循环研究中心, 兰州 730000 \\ *联系人, E-mail: wangna@1zu.edu.cn
}

2013-06-07 收稿, 2013-11-01 接受, 2014-01-03 网络版发表

国家自然科学基金(41371114)、国家环保公益性行业科研专项(201209034)、国家基础科学人才培养基金(J1210065)和教育部高等学校博士 学科点基金(20100211120006)资助

\begin{abstract}
摘要巴丹吉林沙漠腹地高大沙山和湖泊的形成机理一直是学术界研究的热点, 其中关于高大 沙山上大气降水能否入渗补给地下水一直存在较大争议. 本文基于沙漠腹地的 2 年降水观测和 沙漠边缘的长时间尺度降水资料，结合概率分布模型和日降水极值重现期分析，对沙漠地区的 降水等级进行了划分, 并利用沙漠腹地的自动气象站和涡度相关系统的观测数据，对不同等级 降水事件后的沙山蒸发进行分析. 结果显示, 沙漠地区的降水事件可分为 3 类, 即 $5 \mathrm{~mm}$ 以下的 常规降水事件 $\mathrm{CP}$ (占总降水的 $90 \%$ 以上)、20 mm 左右的普通年份最大日降水 OAM 和数十年一 遇的极端强降水事件 EP. CP 和 OAM 事件后, 降水分别约需 1 3 d 和 3 4 周可被蒸发出地表, EP 事件后水分则需较长的时间方可蒸发出地表. 三类降水事件的累积蒸发与累积降水表明, 高大 沙山上的大气降水对地下水没有显著补给作用。本研究对深入探讨巴丹吉林沙漠腹地湖泊群的 形成机理有重要价值.
\end{abstract}

关键词

降水

蒸发

入渗

极值重现期

涡度相关

巴丹吉林沙漠
巴丹吉林沙漠腹地因广泛分布相对高度逾 $300 \mathrm{~m}$ 的高大沙山和众多湖泊, 一直以来都是地学界关注 的热点 ${ }^{[1 ~ 7]}$. 在降水稀少、蒸发力甚大的沙漠腹地, 由 于缺少地表径流, 湖泊的存在必然受到了地下水补 给, 而地下水又源于何处? 早期的学者认为沙漠腹 地的高大沙山具有 “汇水”作用 ${ }^{[8 \sim 11]}$, 即沙丘沙自身较 大的松散性 ${ }^{[7]}$ 可使沙山上的大气降水迅速人渗补给 地下水, 进而补给湖泊, 尽管该区降水稀少, 但沙山 汇水面积约为湖泊面积 10 倍, 故可平衡湖泊的蒸发 损失. Chen 等人 ${ }^{[3]}$ 却指出源于祁连山及青藏高原的冰 雪融水渗漏, 通过断裂带补给了巴丹吉林沙漠地下 水和湖泊. 因此, 巴丹吉林沙漠腹地沙山上的大气降 水能否人渗补给地下水始终存在较大争议. Yang 等 人 $^{[1]}$ 基于水量平衡计算和水化学数据分析结果指出, 巴丹吉林沙漠东南部的地下水主要由大气降水下渗 补给. 赵景波等人 ${ }^{[12]}$ 实测了腹地高大沙山不同部位
沙层剖面含水量的垂直变化趋势, 认为沙漠腹地水 分存在 “正平衡”, 即大气降水可快速人渗至沙山中 下部. 然而, 陈建生等人 ${ }^{[5]}$ 跟踪测量了沙漠腹地降水 事件后的沙层含水量变化, 发现 $10.6 \mathrm{~mm}$ 的降水仅能 下渗至 $13 \mathrm{~cm}$ 深处, 并于 1 周内被逐渐蒸发. 董春 雨 ${ }^{[13]}$ 在该沙漠腹地实施的人工模拟降水实验表明, $30 \mathrm{~mm}$ 的降水仅能下渗 $40 \mathrm{~cm}$ 左右, 不存在继续人渗 补给地下水的可能. 早期的能量平衡试验显示 ${ }^{[6]}$, 由 于沙漠地区蒸发力较强, 巴丹吉林沙漠腹地高大沙 山上的大气降水和凝结水皆可被完全蒸发. 基于上 述不同观点, 本文利用位于巴丹吉林沙漠腹地的自 动气象站和浴度相关系统获得的第一手观测数据, 在揭示腹地降水特征的前提下, 分析腹地不同降水 事件之后的沙山蒸发过程, 旨在为巴丹吉林沙漠腹 地沙山上的大气降水能否人渗补给地下水的研究提 供科学依据. 


\section{1 观测试验与数据处理}

\section{1 观测试验}

巴丹吉林沙漠(图 1)位于中国内蒙古阿拉善高原 西部, 其范围大致为合黎山、北大山以北, 拐子湖、 古居延泽之南, 雅布赖山之西北, 黑河正义峡出山 口、弱水东岸至古日乃湖以东, 东西长约 $442 \mathrm{~km}$, 南 北宽约 $354 \mathrm{~km}$, 面积约 5.21 万 $\mathrm{km}^{2}$, 系中国第二大沙 漠 ${ }^{[14]}$. 该区夏季平均气温 $25.3^{\circ} \mathrm{C}$, 冬季平均气温 $-9.1^{\circ} \mathrm{C}$, 平均气温年较差达 $34.4^{\circ} \mathrm{C}$, 属典型的“冷沙 漠” "[15]. 沙漠南缘年降水量为 90.1 115.4 mm, 北缘仅 $35.2 \sim 42.9 \mathrm{~mm}$, 区域多年平均约 $76.9 \mathrm{~mm}^{[16]}$. 本研究 小组于 2009 年 12 月首先在沙漠腹地的苏木巴润吉林 丘间地处布设了 Vaisala MAWS301 型自动气象站(图 1 , 以下简称 V1 站), 其中降水的观测频率为 $1 \mathrm{~h}$ 一次. 2012 年 3 月 22 日于苏木巴润吉林东部高大沙山的中 下部建立了涡度相关(eddy covariance, EC)系统(图 1, 以下简称 $\mathrm{E} 1$ 站), 拔湖(相对于苏木巴润吉林) 高度为 $80 \mathrm{~m}$, 其中 $\mathrm{CO}_{2} / \mathrm{H}_{2} \mathrm{O}$ 分析仪(Li-Cor, LI-7500A 型)和 三维超声风速仪(GILL, R3-50 型)安装于 $2.5 \mathrm{~m}$ 高处, 观测频率皆为 $10 \mathrm{~Hz}$. 除此之外, 温湿传感器(Vaisala, HMP155 型)安装于 $2 \mathrm{~m}$ 高处, 以观测气温和相对湿 度; 四分量辐射表(Hukseflux, NR01 型)安装于 $1.5 \mathrm{~m}$ 高处, 以观测向上/下短波辐射通量和向上/下长波辐 射通量; 自校准型土壤热通量板(Hukseflux, HFP01SC 型)安装于 $15 \mathrm{~cm}$ 深处以观测土壤热通量; 土壤温度 传感器(Campbell Scientific, ST-100 型)安装于 2 和 $15 \mathrm{~cm}$ 深处(用以估算 $0 \sim 15 \mathrm{~cm}$ 的土壤热通量); 土壤 湿度传感器(Decagon, EC-5 型)分别安装于地下 45 和

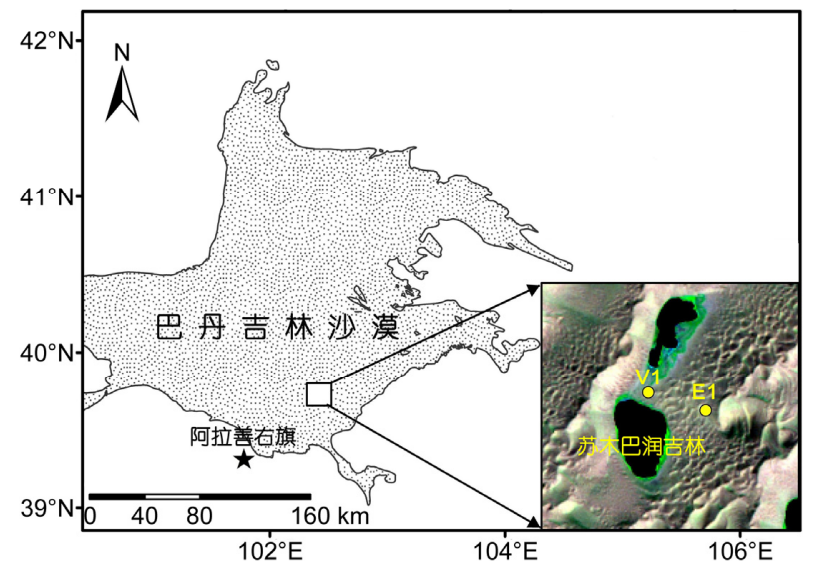

图 1 观测点地理位置示意图
$65 \mathrm{~cm}$ 深处; 上述气温、相对湿度、四分量辐射、土 壤温湿度和土壤热通量皆选用 $30 \mathrm{~min}$ 平均值. 同时, 配备了翻斗式雨量筒(Onset, HOBO R3-GM 型)用于 $\mathrm{E} 1$ 站大气降水的实时观测. 本文所用 V1 站观测的降 水数据起止时间为 2010 年 1 月 1 日 2011 年 12 月 31 日; E1 站的观测数据起止时间为 2012 年 3 月 25 日 10 月 31 日 (其中 2012 年 5 月 9 日 6 月 26 日因 $\mathrm{CO}_{2} / \mathrm{H}_{2} \mathrm{O}$ 分析仪故障导致观测中断). 上述所有沙漠腹地的观 测数据皆以北京时间为准. 另外, 沙漠南缘的阿拉善 右旗气象站(图 1)日降水资料源于中国气象科学数据 共享服务网.

\section{2 数据预处理}

运用 EddyPro Express 软件对 EC 的 $10 \mathrm{~Hz}$ 原始 数据进行了野点去除、趋势订正、二次坐标旋转 ${ }^{[17]}$ 时间延迟修正、感热通量的超声虚温修正 ${ }^{[18]}$ 、频率 响应修正 ${ }^{[19]}$ 和 WPL 修正 ${ }^{[20]}$, 最后求解出 $30 \mathrm{~min}$ 平均 的感热通量 $\mathrm{H}$ 和潜热通量 LE. 与此同时, 基于 Kljun 等人 ${ }^{[21]}$ 提出的通量足迹模型计算了观测期内 $\mathrm{E} 1$ 站的 平均通量源区(flux footprint), 结果显示, 通量的最 大贡献源来自距离观测点东南部 $42.7 \mathrm{~m}$ 处, $90 \%$ 的源 区位于 $116.9 \mathrm{~m}$ 范围内, 而此区域内的地形较为平坦, 基本满足通量观测要求, 且 $\mathrm{E} 1$ 观测点距离湖泊在 $1000 \mathrm{~m}$ 以远, 故本文所用 $\mathrm{EC}$ 的观测数据, 排除了下 垫面非匀质性(指沙漠与湖泊交错)对涡度相关系统 带来的影响 ${ }^{[22]}$, 所测能量与物质通量皆代表典型沙 丘表面. 最后, 在估算了 $0 \sim 15 \mathrm{~cm}$ 土壤热存储的基础 上, 笔者利用 OLS 法 ${ }^{[23]}$ 评估 $\mathrm{EC}$ 数据的整体质量, 得 到该区能量闭合度为 $85.9 \%$ (详细计算过程参见文 献[24]), 与诸多观测试验相近 ${ }^{[23,25,26]}$, 表明 E1 站的 观测数据有较高的可信度.

\section{2 沙漠降水特征}

\section{1 沙漠腹地的降水观测}

准确揭示沙漠腹地大气降水的蒸发与人渗过程 需首先了解腹地的降水规律. 笔者选取 V1 站 2010 年 1 月 1 日 2011 年 12 月 31 日期间的连续观测数据 以分析沙漠腹地降水特征. 由图 3 可见, 沙漠腹地年 降水量和年降水日数(日降水量 $\geqslant 0.1 \mathrm{~mm}$ 为一个降水 日)皆较少, 2010 和 2011 年腹地年降水量分别为 100.6 和 $72.8 \mathrm{~mm}$, 年降水日数分别为 48 和 $23 \mathrm{~d}$. 除此之外, 
沙漠腹地绝大多数(占 $91.5 \%$ ) 日降水量不超过 $5 \mathrm{~mm}$; 单日降水量逾 $20 \mathrm{~mm}$ 的现象较为罕见, 此两年间仅 于 2010 年 5 月 25 日和 9 月 20 日分别出现了 23.8 和 $22.4 \mathrm{~mm}$ 两次较强的降水事件. 对比腹地与外围降水 特征(图 2)可知, 腹地与南缘阿拉善右旗日降水量的 年内降水分布趋势(主要出现在 5 9 月)和日降水量等 级分布(皆以 $\leqslant 5 \mathrm{~mm}$ 为主)极为相似.

\section{2 长时间尺度的沙漠地区日降水量统计特征}

鉴于上述腹地降水分析仅基于 2 年的观测数据, 笔者又统计了沙漠南缘阿拉善右旗气象站 1960 2011 年的日降水数据(图略), 发现其年降水量和年内 降水日数皆有较大波动, 二者变异系数分别为 0.25 和 0.14. 1960 2011 年间, 年降水量变化范围为 $59.2 \sim 188.1 \mathrm{~mm}$, 平均值为 $116.3 \mathrm{~mm}$. 年降水日数介 于 $28 \sim 54 \mathrm{~d}$, 平均 $40 \mathrm{~d} \mathrm{a}^{-1}$, 亦即沙漠地区一年中约 $10 \%$ 的天数发生降水. 除此之外, 就年内最大日降水 量(annual maximum, AM)而言, 1960 2011 年间, 有 $24 \mathrm{a}$ 的 $\mathrm{AM}$ 小于 $20 \mathrm{~mm}$; 另外的 28 个统计年中, 每 年日降水 $\geqslant 20 \mathrm{~mm}$ 的现象亦仅 1 3 次(图 3). 上述分析, 一方面表明腹地的 2 年降水观测结果与沙漠地区降 水的平均状态较为接近, 可代表腹地的降水特征; 另 一方面，也证明笔者推出的巴丹吉林沙漠“日降水多 为 $5 \mathrm{~mm}$ 以下, 大于 $20 \mathrm{~mm}$ 的现象较为罕见”之结论 有较高的可信度, Zhao 等人 ${ }^{[27]}$ 在该沙漠邻近地区的 研究亦支持这一结论.

就强降水而言, 1960 2011 年间阿拉善右旗气象 站日降水 30 40 mm 的事件仅有 7 次, $40 \mathrm{~mm}$ 以上仅 2 次(其中发生于 1974 年 7 月 30 日的 $50.3 \mathrm{~mm}$ 降水
事件是沙漠地区近 52 年的最大日降水), 可见沙漠地 区发生强降水的频率极低. 关于中国塔克拉玛干沙 漠 ${ }^{[28]}$ 、南美阿塔卡马沙漠 ${ }^{[29]}$ 的强降水研究亦有类似 结论. 与此同时, 为了重建降水极值分布特征, 笔者 对阿拉善右旗气象站 1960 2011 年间各年 AM 序列 进行频率分布统计 ${ }^{[30]}$, 对比了 60 种概率分布模型的 拟合效果，并用 Kolmogorov-Smirnov 法检验各概率 分布模型的拟合优度 ${ }^{[31,32]}$, 比较各模型的理论分布 函数与经验分布函数的差值 $D^{[32]}$, 结果发现, 四参数 的 Burr 概率分布对应的差值最小 $(D=0.05561)$, 其拟 合效果最优(图 4), 且置信水平在 $99 \%$ 以上. 按照极 值重现期的定义 ${ }^{[33]}$, 如果某一气候要素极值的概率 分布函数为 $F(x)$, 那么该气候要素极值 $T$ 年一遇的重 现期为 $T=1 / F(x)$. 据图 4 计算, 阿拉善右旗 50 年(即 $F(x)=0.02)$ 一遇的年内最大日降水 $\mathrm{AM} \geqslant 45.3 \mathrm{~mm}$. 与 此同时, $A M \geqslant 20 \mathrm{~mm}$ 的概率为 0.335 , 表明理论上巴 丹吉林沙漠约每 3 年才出现 1 次日降水超过 $20 \mathrm{~mm}$ 的现象.

\section{3 沙漠腹地陆面蒸发特征}

基于上述巴丹吉林沙漠降水特征的分析, 笔者 将该沙漠降水分为 3 种: (1) 常规降水事件(conventional precipitation, $\mathrm{CP}$ ), 指小于 $5 \mathrm{~mm}$ 的降水事件, 腹地约 90\%的降水记录皆属此类(图 2); (2) 普通年份的最大 日降水(ordinary annual maximum, OAM), 即约 $20 \mathrm{~mm}$ 的降水事件, 过去 52 年来, 部分年份可发生 1 3 次 OAM 事件, 部分年份甚至无此现象(图 3); (3) 极端 强降水事件(extreme precipitation, EP), 指 $40 \mathrm{~mm}$ 以 上的降水事件，其出现的概率极低，属几十年一遇的
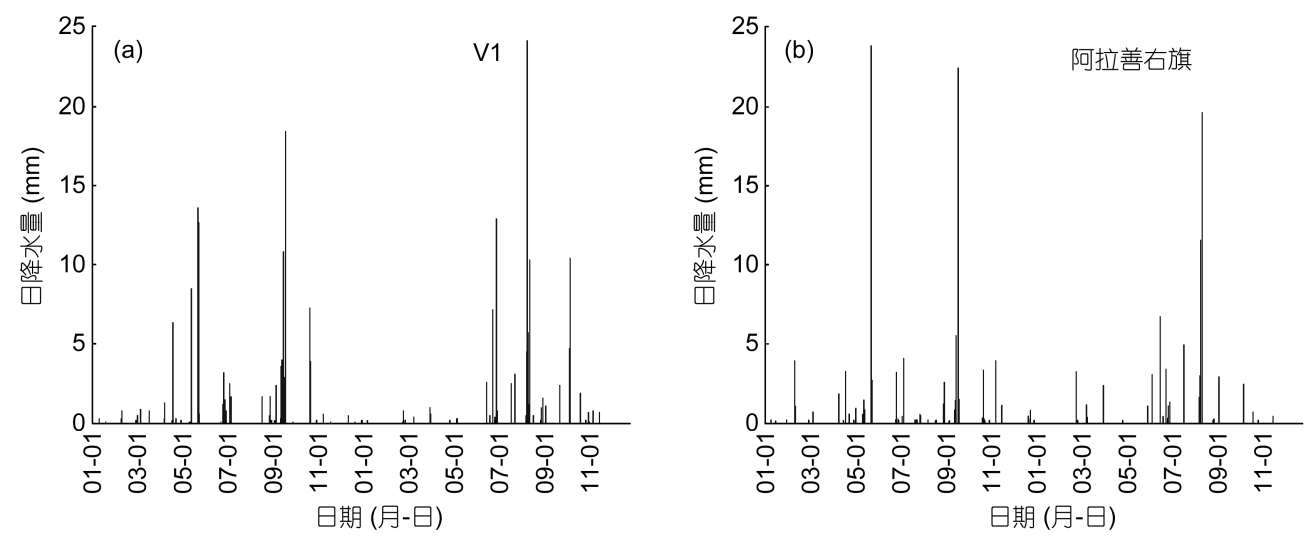

图 22010 2011 年沙漠腹地 V1 站(a)与沙漠南缘阿拉善右旗气象站(b)日降水量 


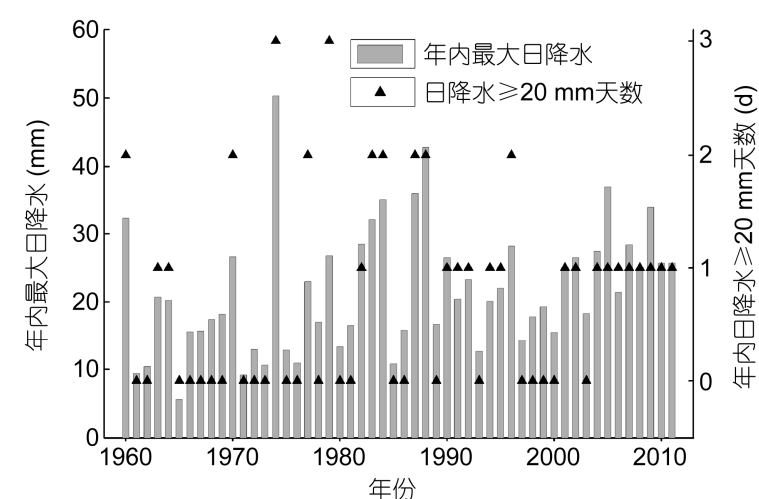

图 3 阿拉善右旗 1960 2011 年内最大日降水分布及每年日 降水 $\geqslant 20 \mathrm{~mm}$ 天数

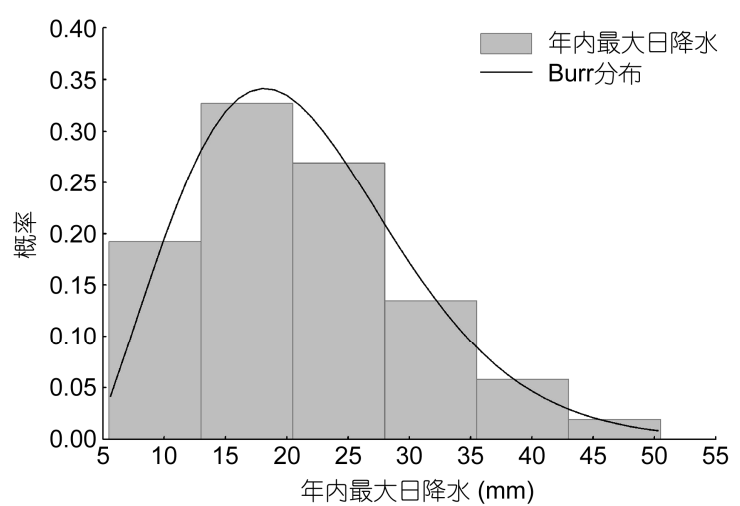

图 4 阿拉善右旗年内最大日降水频率分布(柱状)与四参数 Burr 拟合(曲线)

现象, 例如 1960 2011 年间, 沙漠南缘的阿拉善右旗 仅发生 2 次极端强降水事件(图 3).

\section{1 常规降水事件 CP 后的沙漠陆面蒸发}

2012 年 4 月 11 日 09:56 11: 15 沙漠腹地发生了 1 次 $4.0 \mathrm{~mm}$ 的降水事件(图 5(a)). EC 在降水结束 $4 \mathrm{~h}$
后即恢复正常观测(图 5(b)), 结果显示, 16:00 时沙漠 地表的潜热通量 LE 最高可达 $500 \mathrm{~W} \mathrm{~m}^{-2}$, 波文比 (H/LE) 甚至小于 0.1 , 远低于晴天沙漠地区波文比. 时至夜晚地表温度开始降低, 因降水后空气中水汽 含量较大, 当地表温度降至露点温度以下时, 出现明 显的凝结现象 (即 LE 为负). 4 月 12 日上午 LE 逐渐升 高, 暗示强烈的蒸发作用仍在持续. 结合累积蒸发量 可见(图 5(b))，从 4月 11日 16:00 4月 12日 14:00(共 $22 \mathrm{~h}$ )累积蒸发即超过 $4.0 \mathrm{~mm}$, 表明 $4 \mathrm{~mm}$ 的降水事件 结束后的 $1 \mathrm{~d}$ 内, 其水分即被全部蒸发.

\section{2 普通年份最大日降水事件 OAM 后的沙漠陆 面蒸发}

2012 年 6 月 27 日 $02: 37 \sim 12: 19$ 发生 1 次 $12.6 \mathrm{~mm}$ 的降水事件(持续时间约 $10 \mathrm{~h}$ ), 6月 28日 17:13 20:09 发生 1 次 $7.8 \mathrm{~mm}$ 的降水事件(持续时间约 $3 \mathrm{~h}$ ), 相隔 $1 \mathrm{~d}$ 的 2 次降水事件累积降水量达 $20.4 \mathrm{~mm}$ (图略), 笔 者将 2 次降水事件作为一个整体, 按沙漠地区普通年 份的最大日降水量 OAM 分析.

由图 6(a)可见, 6 月 27 日中午降水停止后的 $12 \mathrm{~h}$ 内, 陆面蒸发量即达 $2.3 \mathrm{~mm}$, 之后的 6 月 28 日(辐射 观测显示为阴天)亦有 $2.8 \mathrm{~mm}, 6$ 月 29 日蒸发量甚至 达到 $3.6 \mathrm{~mm}$, 但之后随着沙山表层含水量的减小, 蒸发亦开始减小. 截至 7月 3日 15:00 再次发生降水 之前, 其累积蒸发量达 $13.4 \mathrm{~mm}$, 暗示降水结束后约 $6 \mathrm{~d}$ 内已有 $2 / 3$ 的降水被蒸发. 地表蒸发速率随 7 月 6 日降水事件而增大, 之后亦逐渐减小, 7 月 17 日与之 类似(图 6(a)). 总体而言, 从 2012 年 6 月 27 日 0 时 7月 20 日 12 时(7月 20 日 12 时以后即出现强降水), 观测点 $\mathrm{E} 1$ 处累积降水量 $28.0 \mathrm{~mm}$, 而累积蒸发为 $26.2 \mathrm{~mm}$ (图 6(b)), 仅剩余 $1.8 \mathrm{~mm}$ 尚未蒸发出地表,
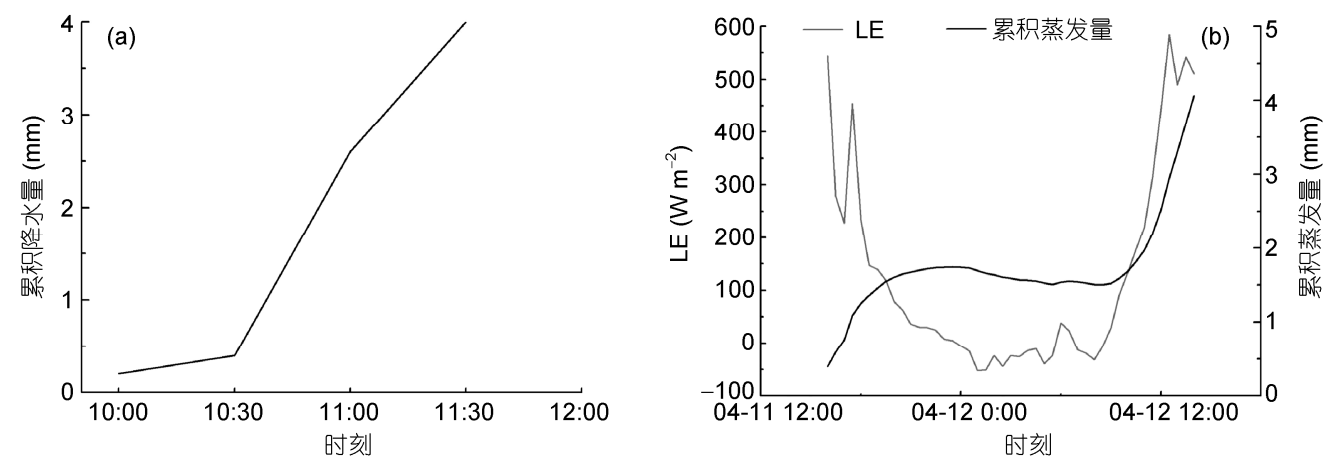

图 52012 年 4 月 11 日 E1 站降水历时曲线(a)和降水结束后的 LE 与累积蒸发(b) 

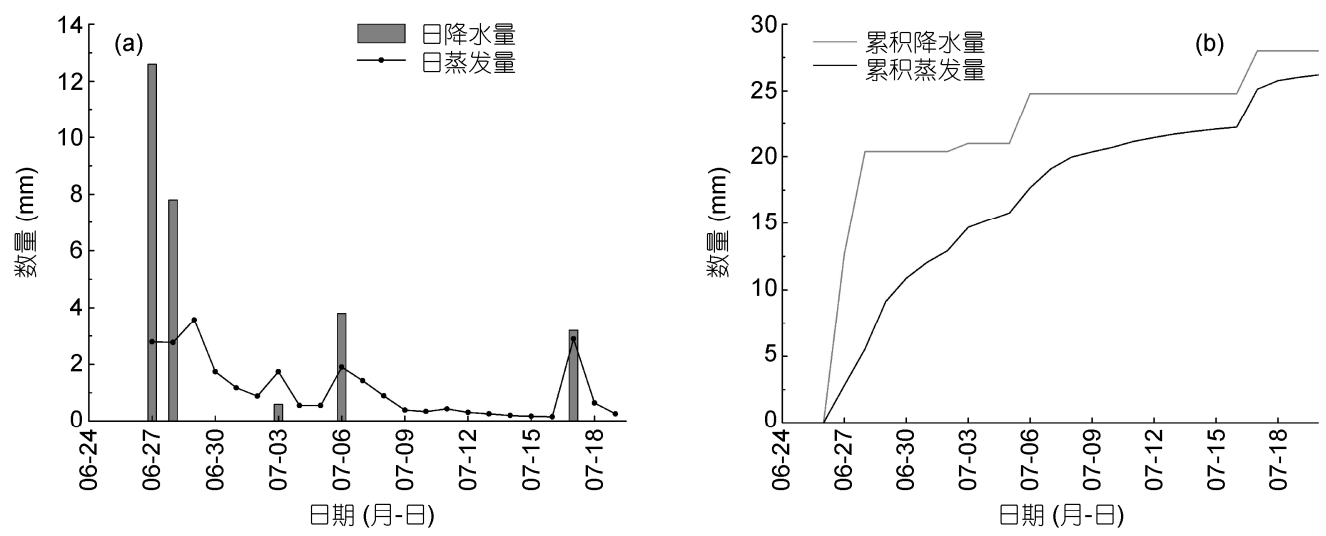

图 62012 年 6 月 27 日 0:00 7 月 20 日 12:00 期间 E1 站日降水与日蒸发(a)以及累积降水与累积蒸发(b)

倘若延续无降水现象，应于一周内即可完全蒸发. 另 一方面，上述时间段内土壤湿度观测表明(图 7), 45 $\mathrm{cm}$ 深处沙层体积含水量略有增大, 而 $65 \mathrm{~cm}$ 深处沙层 体积含水量始终未见明显变化, 暗示该时段内湿润 锋前到 45 65 cm 之间, 亦即 $20 \mathrm{~mm}$ 左右的大气降水 未人渗至 $65 \mathrm{~cm}$ 以下, 所以不可能对地下水有补给作 用. 陈建生等人 ${ }^{[5]}$ 亦曾对该沙漠降水事件后的地表湿 沙层进行连续测量, 指出 $10.6 \mathrm{~mm}$ 的大气降水只能渗 人地下 $13 \mathrm{~cm}$ 左右, 且在降水结束后 1 周内被蒸发出 地表, 这与本文结果较为一致.

\section{3 极端强降水事件 EP 后的沙漠陆面蒸发}

2012 年 7 月 20 日中午起, 沙漠腹地发生了 1 次 $43 \mathrm{~mm}$ 的极端强降水事件 EP. 该降水事件发生于 12:42 18:06, 期间 13:00 14:00 的小时降水量达 26 $\mathrm{mm}$, 略大于塔克拉玛干沙漠腹地曾报道的 $19.6 \mathrm{~mm} \mathrm{~h}^{-1}$

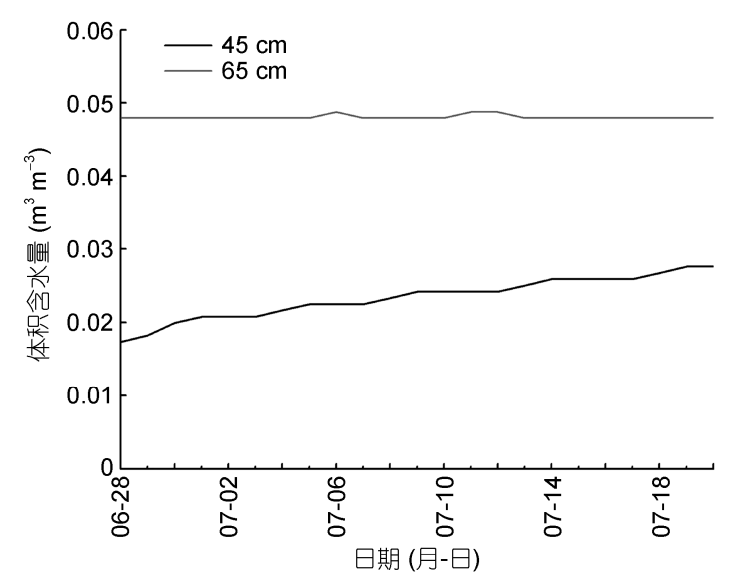

图 72012 年 6 月 28 日 0:00 7 月 20 日 0:00 期间 E1 站 45 和 $65 \mathrm{~cm}$ 处沙层体积含水量变化
的降水强度 ${ }^{[34]}$. 当日处于沙漠南缘的阿拉善右旗气象 站亦有 $48.8 \mathrm{~mm}$ 的降水记录, 证明腹地观测较为准确.

7 月 20 日降水结束后的第一天 (即 7 月 21 日), 陆 面蒸发量达 $3.3 \mathrm{~mm}$, 随后的 $5 \mathrm{~d}$ 内, 日蒸发量平均可 达 $1.7 \mathrm{~mm}$, 指示强烈的蒸发过程. 随着表层含水量 的逐渐降低, 地表蒸发速率减缓, 因此 7 月 27 28 日 蒸发量降至 $0.5 \mathrm{~mm}$ 左右. 与此同时, 随着降水的再 次发生, 陆面蒸发回升, 持续一段时间后蒸发又逐渐 减小(图 8(a)). 需要指出, 即便蒸发较为缓慢, 然因 湿沙层水分含量较小, 故必然不足以下渗补给地下 水. 当然, 越强的降水事件会使渗人沙层的深度越大, 故其蒸发出地表所需之时间亦越长, 但很难能下渗 数米深而补给地下水. 具体而言, 从 7 月 20 日起进行 累积蒸发至 9 月 1 日的 $43 \mathrm{~d}$ 内(图 8(b)), 累积蒸发即 达到 $45.5 \mathrm{~mm}$, 超过了极端降水事件的 $43 \mathrm{~mm}$, 暗示 EP 降水已被蒸发出地表.

\section{4 讨论}

尽管存在能量不闭合现象 ${ }^{[23]}$ 和 EC 自身的随机 误差 ${ }^{[35]}$, 然而 $\mathrm{EC}$ 仍被视为测量生态系统蒸散发最为 准确的手段之一 ${ }^{[36]}$, 并在森林 ${ }^{[37]}$ 、草原 ${ }^{[38,39]}$ 、农田 ${ }^{[26]}$ 、 荒漠 ${ }^{[40,41]}$ 等蒸散发研究中得到了广泛应用. 本文利 用位于沙漠腹地沙山中下部的 EC 所测数据分析了不 同降水事件后的沙山蒸发过程, 结果显示, 即便是大 于 $40 \mathrm{~mm}$ 的极端降水事件, 水分亦难以人渗补给地 下水, 表明巴丹吉林沙漠腹地湖泊水分主要来源并 非大气降水. 需要指出, 沙漠腹地的降水历时一般较 短, 而陆面蒸发系持续性过程. 例如, 就强降水事件 后累积降水与累积蒸发的变化而言(图 8(b)), 随时间 推移, 二者之差逐渐减小, 表明极端降水事件后, 湿 

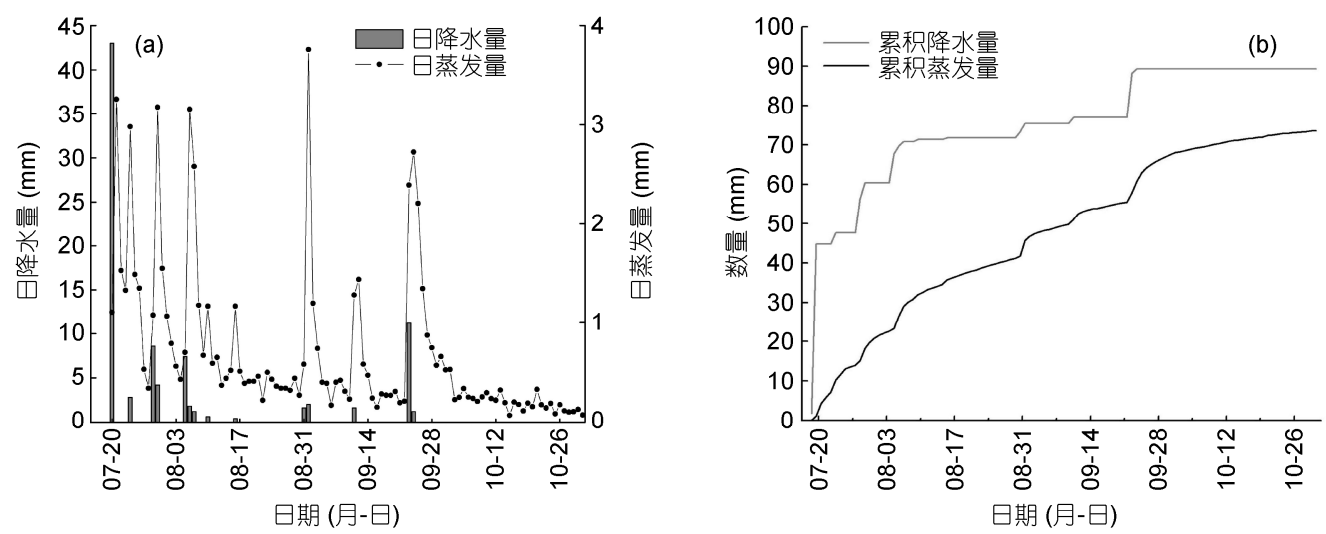

图 82012 年 7 月 20 日 10 月 31 日 E1 站日降水与日蒸发 $(a)$ 和累积降水与累积蒸发(b)

润锋首先前进至沙层的某一深度, 然而累积蒸发一 直“追赶”累积降水，暗示降水又被逐渐蒸发出地表.

在降水稀少的干旱地区, 研究大气降水能否人 渗补给地下水对当地水资源的合理利用有重要意义. $\mathrm{Xu}$ 等人 ${ }^{[42]}$ 基于矩阵分布式蒸渗仪的观测结果指出, 河西沙漠地区至少 $91 \%$ 的降水会被蒸发出地表, 剩 余部分则保存于沙层中. 毛乌素沙地的蒸发人渗实 验显示, $10 \mathrm{~mm}$ 的降水可于 $15 \mathrm{~d}$ 内蒸发出地表 ${ }^{[43]}$. 黄 土高原地区土壤水、大气降水和地下水的稳定氢氧同 位素和水化学数据分析表明, 当地的大气降水不能 人渗补给地下水 ${ }^{[44]}$. 然而本课题组在巴丹吉林沙漠 的野外考察发现，一般情况下地表的干沙层仅仅厚 $20 \mathrm{~cm}$ 左右, 其下即为明显的湿沙层. 顾慰祖等人 ${ }^{[6]}$ 所测高大沙山 $2 \mathrm{~m}$ 深处孔隙水含水量可达沙丘田间 持水量的 $65 \%$, 绝非沙漠地区稀少的降水量所能支 持的. 早期的高大沙山陆面能量平衡实验表明, 沙山 的年蒸发量大于凝结水与大气降水之和, 故有学者 推测沙山下部的地下水补给了陆面蒸发 ${ }^{[6]}$. Chen 等

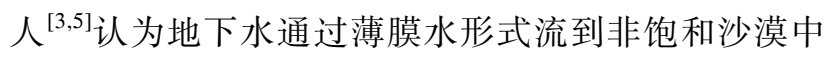
形成湿沙层, 湿沙层的薄膜水通过蒸发向地表排泄, 沙山湿沙层的水分源于地下水, 地下水将沙颗粒黏 结在一起, 大大提高抵抗风蚀的能力, 形成了固定沙 山, 即地下水维系了高大沙山和湖泊景观. 同位素研 究结果表明, 巴丹吉林沙漠地下水的氞氧同位素值 异常 ${ }^{[1,5]}$, 偏离全球大气降水线 ${ }^{[3,5]}$, 暗示该沙漠腹地
的地下水受到强烈蒸发, 并得到了沙层 $40 \mathrm{~cm}$ 以下的 土壤水中忥氧同位素分析的验证 ${ }^{[45]}$. 相关研究表明, 在临界蒸发深度以上, 埋深越大的潜水蒸发越 弱 ${ }^{[46,47]}$. 本研究中 E1 站位于苏木巴润吉林东部高大 沙山的中下部, 海拔较该湖高 $80 \mathrm{~m}$, 地下水埋深较 大, 受到的干扰因素与不确定性增大, EC 在长时期 无降水背景下测定的沙漠蒸发受到限制.

\section{5 初步结论}

(1) 巴丹吉林沙漠腹地 2 年的降水观测和沙漠边 缘长时间尺度的降水资料分析表明，该沙漠地区降 水可划为 3 类: (1) 小于 $5 \mathrm{~mm}$ 的常规降水事件 $\mathrm{CP}$, 占沙漠地区降水的 $90 \%$ 以上; (2) 普通年份的最大日 降水 OAM, 指 $20 \mathrm{~mm}$ 左右的降水事件, 约每 3 年发 生 1 次; (3) 极端强降水事件 EP, 指 $40 \mathrm{~mm}$ 以上的降 水事件, 系数十年一遇的现象.

(2) 据位于高大沙山中下部的 $\mathrm{EC}$ (拔湖高度 $80 \mathrm{~m}$ ) 和降水观测数据分析显示, 沙山上的常规降水事件 (CP) 和普通年份的最大日降水 $(\mathrm{OAM})$ 皆不能人渗补 给地下水, 前者在 1 3 d 内可被完全蒸发, 后者约 3 4 周可被完全蒸发. 数十年一遇的极端强降水事件 $\mathrm{EP}$ 后, 水分渗人沙层的深度较大, 需较长的时间方 可蒸发出地表, 但亦不会人渗补给对地下水. 总之, 巴丹吉林沙漠腹地高大沙山上的大气降水对地下水 没有显著补给作用. 
1 Yang X P, Ma N, Dong J F, et al. Recharge to the inter-dune lakes and Holocene climatic changes in the Badain Jaran Desert, western China. Quat Res, 2010, 73: 10-19

2 王乃昂, 马宁, 陈红宝, 等. 巴丹吉林沙漠腹地降水特征初步分析. 水科学进展, 2013, 24: 153-160

3 Chen J S, Li L, Wang J Y, et al. Groundwater maintains dune landscape. Nature, 2004, 432: 459

4 Chen J S, Zhao X, Sheng X F, et al. Geochemical information indicating the water recharge to lakes and immovable megadunes in the Badain Jaran Ddesert. Acta Geol Sin, 2005, 79: 540-546

5 陈建生, 赵霞, 盛雪芬, 等. 巴丹吉林沙漠湖泊群与沙山形成机理. 科学通报, 2006, 51: 2789-2796

6 顾慰祖，陈建生，汪集旸，等. 巴丹吉林高大沙山表层孔隙水现象的疑义. 水科学进展, 2004, 15: 695-699

7 Yang X P, Williams M A. The ion chemistry of lakes and late Holocene desiccation in the Badain Jaran Desert, Inner Mongolia, China. Catena, 2003, 51: 45-60

8 王涛. 巴丹吉林沙漠形成演变的若干问题. 中国沙漠, 1990, 10: 29-40

9 孙培善, 孙德钦. 内蒙古高原西部水文地质初步研究. 见: 中国治沙队, 编. 治沙研究(第六号). 北京: 科学出版社, 1964. 245-317

10 Jaeckel D. The Badain Jaran Desert: Its origin and development. Geowissenschaften, 1996, 14: 272-274

11 Jakel D. The importance of dunes for groundwater recharge and storage in China. Z Geomorphol, 2002, 126(Suppl): 131-146

12 赵景波, 邵天杰, 侯雨乐, 等.巴丹吉林沙漠高大沙山区沙层含水量与水分来源探讨. 自然资源学报, 2011, 26: 694-702

13 董春雨. 阿拉善沙漠沙漠水循环观测实验与湖泊水量平衡. 硕士学位论文. 兰州: 兰州大学, 2011

14 朱金峰，王乃昂，陈红宝，等. 基于遥感的巴丹吉林沙漠范围与面积分析. 地理科学进展, 2010, 29: 1087-1094

15 Warner T T. Desert Meteorology. Cambridge: Press Syndicate of the University of Cambridge, 2004

16 马宁, 王乃昂, 朱金峰, 等. 巴丹吉林沙漠周边地区近 50a 来气候变化. 中国沙漠, 2011, 31: 1541-1547

17 Aubinet M, Grelle A, Ibrom A, et al. Estimates of the annual net carbon and water exchange of European forests: The EUROFLUX methodology. Adv Ecol Res, 2000, 30: 113-175

18 Dijk A V, Moene A F, DeBruin H A R. The Principles of Surface Flux Physics: Theory, Practice and Description of the ECPACK Library. Wageningen: Meteorology and Air Quality Group of Wageningen University, 2004

19 Moncrieff J B, Clement R, Finnigan J, et al. Averaging, detrending and filtering of eddy covariance time series. In: Lee X, Massman W J, Law B E, eds. Handbook of Micrometeorology: A Guide for Surface Flux Measurement. Dordrecht: Kluwer Academic, 2004. 7-31

20 Webb E K, Pearman G I, Leuning R. Correction of flux measurements for density effects due to heat and water vapour transfer. Quat J Res Meteorol Soc, 1980, 106: 85-100

21 Kljun N, Calanca P, Rotach M W, et al. A simple parameterisation for flux footprint predictions. Bound-Layer Meteorol, 2004, 112: 503-523

22 Stoy P C, Mauder M, Foken T, et al. A data-driven analysis of energy balance closure across FLUXNET research sites: The role of landscape scale heterogeneity. Agric For Meteorol, 2013, 171: 137-152

23 Wilson K, Goldstein A, Falge E, et al. Energy balance closure at FLUXNET sites. Agric For Meteorol, 2002, 113: 223-243

24 马宁. 巴丹吉林沙漠能量分配与湖泊蒸发量的观测研究. 硕士学位论文. 兰州: 兰州大学, 2012

25 Oncley S P, Foken T, Vogt R, et al. The energy balance experiment EBEX-2000. Part I: Overview and energy balance. Bound-Layer Meteorol, 2007, 123: 1-28

26 Liu S M, Xu Z W, Zhu Z L, et al. Measurements of evapotranspiration from eddy-covariance systems and large aperture scintillometers in the Hai River Basin, China. J Hydrol, 2013, 487: 24-38

27 Zhao W Z, Liu B. The response of sap flow in shrubs to rainfall pulses in the desert region of China. Agric For Meteorol, 2010, 150: 1297-1306

28 何清, 向鸣, 李立. 塔克拉玛干沙漠腹地一次强降水天气分析. 干旱区研究, 1998, 15: 15-20

29 Houston J. Variability of precipitation in the Atacama desert: Its cause and hydrological impact. Int J Climatol, 2006, 26: 2181-2198

30 Jenkinson A F. The frequency distribution of the annual maximum (or minimum) values of meteorological elements. Quat J Res Meteorol Soc, 1955, 81: 158-171

31 Justel A, Pena D, Zamar R. A multivariate Kolmogorov-Smimov test of goodness of fit. Stat Probabil Lett, 1997, 35: 251-259

32 Zhang Q, Xu C Y, Chen Y D, et al. Extreme value analysis of annual maximum water levels in the Pearl River Delta, China. Front Earth Sci China, 2009, 3: 154-163

33 Xia J, She D X, Zhang Y Y, et al. Spatio-temporal trend and statistical distribution of extreme precipitation events in Huaihe River Basin during 1960-2009. J Geogr Sci, 2012, 22: 195-208 
34 李江风. 大漠腹地暴雨与积水. 新疆气象, 1990, 13: 47

35 Foken T, Wichura B. Tools for quality assessment of surface-based flux measurements. Agric For Meteorol, 1996, 78: 83-105

36 Baldocchi D D, Falge E, Gu L H, et al. FLUXNET: A new tool to study the temporal and spatial variability of ecosystem-scale carbon dioxide, water vapor, and energy flux densities. Bull Amer Meteorol Soc, 2001, 82: 2415-2434

37 Malhi Y, Pegoraro E, Nobre A D, et al. Energy and water dynamics of a central Amazonian rain forest. J Geophys Res, 2002, 107, doi: 10.1029/2001JD000623

38 Yang F L, Zhou G S. Characteristics and modeling of evapotranspiration over a temperate desert steppe in Inner Mongolia, China. J Hydol, 2011, 396: 139-147

39 Krishnan P, Meyers T P, Scott R L, et al. Energy exchange and evapotranspiration over two semi-arid grasslands in North America. Agric For Meteorol, 2012, 153: 31-44

40 Kampf S K, Tyler S W, Ortizc C A, et al. Evaporation and land surface energy budget at the Salar de Atacama, Northern Chile. J Hydol, 2005, 310: 236-252

41 Unland H E, Houser P R, Shuttleworth W J, et al. Surface flux measurement and modeling at a semi-arid Sonoran Desert site. Agric For Meteorol, 1996, 82: 119-153

42 Xu X Y, Zhang R D, Xue X Z, et al. Determination of evapotranspiration in the desert area using lysimeters. Commun Soil Sci Plan, 1998, 29: $1-13$

43 原鹏飞, 丁国栋，王炜炜，等. 毛乌素沙地降雨人渗和蒸发特征. 中国水土保持科学, 2008, 6: 23-27

44 Chen J S, Liu X Y, Wang C Y, et al. Isotopic constraints on the origin of groundwater in the Ordos Basin of northern China. Environ Earth Sci, 2012, 66: 505-517

45 Chen J S, Sun X X, Gu W Z, et al. Isotopic and hydrochemical data to restrict the origin of the groundwater in the Badain Jaran Desert, Northern China. Geochem Int, 2012, 50: 455-465

46 张光辉，聂振龙，王金哲，等．黑河流域水循环过程中地下水同位素特征及补给效应．地球科学进展, 2005, 20: 511-519

47 张永明, 胡顺军, 翟禄新, 等. 塔里木盆地裸地潜水蒸发计算模型. 农业工程学报, 2009, 25: 27-32 